Artículo de investigación

\title{
Incidencia de Escherichia coli 0157:H7 en heces de rumiantes lactantes con síndrome diarreico
}

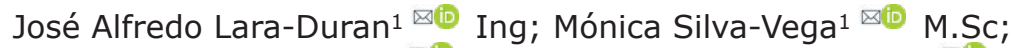 \\ Rómulo Bañuelos-Valenzuela ${ }^{1}$ (1) Ph.D; Lucía Delgadillo-Ruiz ${ }^{2 *} \bowtie(1)$ Ph.D; \\ Olivia Delgadillo-Ruiz ${ }^{\boxplus(\mathbb{0}}$ Ph.D.
}

\begin{abstract}
${ }^{1}$ Universidad Autónoma de Zacatecas, Unidad Académica de Medicina Veterinaria y Zootecnia, Km 31.5 de la carretera panamericana tramo Zacatecas-Fresnillo, Enrique Estrada, Zacatecas, México.

¿2Universidad Autónoma de Zacatecas, Unidad Académica de Ciencias Biológicas, Avenida preparatoria s/n colonia Hidráulica, Zacatecas , Zacatecas, México.

${ }^{3}$ CONACYT-Consorcio CENTROMET, Camino a Los Olvera \#44, Corregidora, Querétaro, México.

*Correspondencia: delgadillolucia@gmail.com
\end{abstract}

Recibido: Agosto 2018; Aceptado: Junio 2019; Publicado: Septiembre 2019.

\section{RESUMEN}

Objetivo. Identificar Escherichia coli 0157:H7 presente en heces diarreicas de rumiantes lactantes con síndrome diarreico y seguridad de ingesta de calostro. Materiales y métodos. Se realizó un muestreo de 316 rumiantes durante el período de agosto 2015 a marzo 2016 en los municipios de Río Grande, General Enrique Estrada, Morelos y Calera de Víctor Rosales del estado de Zacatecas, 67 de bovinos, 183 de ovinos y 66 de caprinos. Resultados. Se identificaron en medio cromogénico CHROMagarTM: 260 coliformes, 78 Escherichia coli O157:H7, 16 Proteus spp., y 25 colonias de bacterias sin identificar con este medio, encontrándose una incidencia de Escherichia coli O157:H7 de 22.03\% en los cuatro municipios. Conclusiones. Escherichia coli $\mathrm{O} 157: \mathrm{H} 7$ es la segunda bacteria encontrada en heces de rumiantes con un $22 \%$ de incidencia, la cual es un factor de riesgo de muerte en rumiantes lactantes (menos de 21 días de nacidos) causando pérdidas económicas y riesgo para la salud de la población del estado de Zacatecas.

Palabras clave: Bacterias, medio cromogénico, ovinos (Fuente: CAB).

\section{ABSTRACT}

Objective. To identify Escherichia coli 0157:H7 present in diarrheal feces of lactating ruminants (less than 21 days old) with diarrheal syndrome and safety of colostrum intake. Materials and methods. A feces sampling of 316 ruminants was carried out during the period of August 2015 to March 2016 in the municipalities of Río Grande, General Enrique Estrada, Morelos and Calera de Victor Rosales of the state of Zacatecas, obtained from 67 cattle, 183 sheep and 66 goats. Results. The following were identified in CHROMagarTM chromogenic medium: 260 coliforms, 78 Escherichia coli 0157:H7, 16 Proteus spp. and 25 colonies of unidentified bacteria, finding an incidence of Escherichia coli $0157: \mathrm{H} 7$ of $22.03 \%$ in the four municipalities. Conclusions. Escherichia coli 0157:H7 is the second bacteria found in ruminant feces with an incidence of $22 \%$, which is a mortality risk factor in lactating ruminants (less than 21 days old), causing economic loss and health risk for the population of the state of Zacatecas.

Keywords: Bacteria, chromogenic medium, sheep (Source: $C A B$ ).

Como citar (Vancouver)

Lara-Duran JA, Silva-Vega M, Bañuelos-Valenzuela R, Delgadillo-Ruiz L, Delgadillo-Ruiz O. Incidencia de Escherichia coli O157:H7 en heces de rumiantes lactantes con síndrome diarreico. Rev MVZ Cordoba. 2019; 24(3):7339-7345. DOI: https://doi.org/10.21897/rmvz.1232

(c)(1) (CEl (los) autor (es), Revista MVZ Córdoba 2019. Este artículo se distribuye bajo los términos de la licencia internacional Creative Commons Attribution 4.0 (https://creativecommons.org/licenses/by-nc-sa/4.0/), que permite a otros distribuir, remezclar, retocar, y crear a partir de su obra de modo no comercial, siempre y cuando den crédito y licencien sus nuevas creaciones bajo las mismas condiciones. 


\section{INTRODUCCIÓN}

La repercusión económica por problemas de enfermedades digestivas en los rumiantes en México es grave y frecuente. Los síntomas patológicos que presentan los rumiantes bajo ese estrés son: bajo consumo de alimento, presencia de diarreas (o disentería), acidosis ruminal, laminitis, cojera, retraso en el desarrollo corporal de corderos, cabritos y terneros (1). Esto se traduce en un costo extra que el productor no tiene contemplado, además, de los gastos en tratamientos veterinarios (2).

En los sistemas de producción intensivos, el índice de corderos muertos por enfermedades digestivas antes del destete llega a ser menor al 10\%, mientras que en sistemas extensivos las pérdidas representan hasta un $53 \%$ de los corderos nacidos (3). No obstante, en diversos reportes se menciona que los procesos infecciosos y los trastornos de tipo nutricional y metabólicos representan la principal causa de mortalidad neonatal (4). De hecho, entre un 15 y $20 \%$ de las pérdidas neonatales pueden ser atribuidas a enfermedades digestivas, y en consecuencia, el resto (alrededor de $80 \%$ ) se deben a factores ambientales o de manejo (3).

Los Centros para el Control y Prevención de Enfermedades (CDC por sus siglas en inglés) del Departamento de Salud y Servicios Humanos de los Estados Unidos de América mencionan que Escherichia coli es una bacteria que normalmente vive en los intestinos de personas y animales. En su mayoría son inofensivas y en realidad son parte del tracto intestinal sano. Sin embargo, algunos serotipos son patógenos, causando diarreas 0 enfermedades fuera del tracto intestinal (5).

Escherichia coli se clasifica en seis serotipos que se asocian con diarrea; entre estos se encuentra Escherichia coli enterohemorragica (EHEC), la cual es causante de colitis hemorrágica $(\mathrm{HC})$ y se identifica mediante la producción de toxinas Shiga (Stxs). Escherichia coli productora de toxinas Shiga (STEC) es un grupo de patógenos zoonóticos y Escherichia coli 0157:H7 es el serotipo asociado con colitis hemorrágica y síndrome urémico hemolítico (HUS), principalmente en los Estados Unidos de América (6).

Laven et al (7) demostraron que la presencia de Escherichia coli en rumiantes fue más alta en el colon que en el rumen, asociándose la presencia de Escherichia coli con la fase de ingesta y no con la pared intestinal del rumen. Estudios han demostraron que la parte terminal del colon es el principal sitio de desarrollo de la colonización de Escherichia coli 0157:H7 y que el tejido linfoide localizado en la unión recto-anal es el sitio de la colonización en el ganado (8), por lo que, esta colonización es considerada como un "super-propagador" que causa severas infecciones con cuadros epidémicos caracterizados por diarreas hemorrágicas, colitis y síndrome urémico hemolítico (9).

El aislamiento adecuado y los métodos de identificación son cruciales para diagnosticar Escherichia coli O157:H7. Antes de confirmar su presencia en una muestra es necesario aislarla e identificarla en medios de cultivos selectivos y diferenciales. Los medios usados convencionalmente para el aislamiento de Escherichia coli 0157:H7 incluyen Sorbitol MacConkey Agar (SMAC), CefiximeTellurite Sorbitol MacConkey Agar (CTSMAC), CHROMagarTM O157 (CHROMagar), Tellurite CHROMagar ${ }^{T M}$ O157 (T-CHROMagar) y Vancomicina Cefixima Cefsoludina CHROMagarTM O157 (VCCCHROMagar) $(6,10)$.

Los sustratos químicos cromogénicos patentados para la identificación de colonias microbianas desencadenaron el desarrollo de una amplia gama de medios para la detección de patógenos. El medio $\mathrm{CHROMagar}^{\mathrm{TM}} \mathrm{O} 157$ promueve selectivamente el crecimiento de Escherichia coli 0157:H7 y la diferencia de Escherichia coli no 0157, debido a un sustrato cromogénico de $\beta$-galactosidasa y un cambio en el pH (6), utilizándose este medio para la detección de Escherichia coli 0157:H7 tanto en muestras alimentarias como ambientales, pudiendo ser más selectivo con la adición de tellurita de potasio, o bien con vancomicina, cefixima y cefsoludina (11).

Bajo el contexto anterior, se planteó como objetivo identificar Escherichia coli O157:H7 en heces diarreicas de rebaños de rumiantes lactantes menores a 21 días de vida mediante el uso del agar CHROMagarTM, lo que permitirá a los ganaderos tomar decisiones sobre los tratamientos a emplear para evitar la incidencia de este patógeno y disminuir la mortalidad neonatal.

\section{MATERIALES Y MÉTODOS}

Muestras. Se obtuvieron 316 hisopados rectales provenientes de 183 ovinos, 66 de caprinos y 67 de bovinos menores de 21 días de edad y con la seguridad de haber ingerido calostro, con presencia de síndrome diarreico. La colecta de las muestras se realizó vía rectal con un hisopo estéril, se etiquetaron y transportaron en medio Stuar ${ }^{\circledR}$ elaborado en México D.F. El muestreo se realizó durante el período de agosto 2015 a marzo de 2016 en cuatro municipios del estado de Zacatecas: en Calera de Víctor Rosales las localidades El Bordo, Noria de Agostadero, El Duraznillo, El Vergel y El Porvenir: en Morelos las 
localidades de Hacienda Nueva, Noria de Gringos, Las Pilas y El Palmar: en General Enrique Estrada, las localidades de General Enrique Estrada, Los Ángeles, Puentecillos y San Sebastián y: en Río Grande las localidades El Carrizal, Los Ramírez, San José de Ranchitos y Tierra Blanca (Figura 1). (Coordenadas: El Bordo 102 ${ }^{\circ} 49^{\prime} 20^{\prime \prime} O$ $22^{\circ} 57^{\prime} 02^{\prime \prime} \mathrm{N}$, San José de Ranchitos $102^{\circ} 57^{\prime} 35^{\prime \prime O}$ $23^{\circ} 40^{\prime} 0^{\prime \prime} \mathrm{N}$, El Carrizal $103^{\circ} 01^{\prime} 08^{\prime \prime} \mathrm{O} 23^{\circ} 38^{\prime} 25^{\prime \prime} \mathrm{N}$, El Duraznito $102^{\circ} 38^{\prime} 26^{\prime \prime} \mathrm{O} 23^{\circ} 01^{\prime} 29^{\prime \prime} \mathrm{N}$, El Palmar $102^{\circ} 39^{\prime} 58^{\prime \prime} \mathrm{O} 22^{\circ} 53^{\prime} 24^{\prime \prime} \mathrm{N}$, El Porvenir $102^{\circ} 40^{\prime} 00^{\prime \prime} \mathrm{O}$ $22^{\circ} 56^{\prime} 42^{\prime \prime} \mathrm{N}$, El Vergel $102^{\circ} 41^{\prime} 01^{\prime \prime} \mathrm{O} 22^{\circ} 59^{\prime} 58^{\prime \prime} \mathrm{N}$, General Enrique Estrada $102^{\circ} 44^{\prime} 29^{\prime \prime} \mathrm{O} 22^{\circ} 59^{\prime} 40^{\prime \prime} \mathrm{N}$, Hacienda Nueva $102^{\circ} 36^{\prime} 21^{\prime \prime O} 22^{\circ} 49^{\prime} 30^{\prime \prime} \mathrm{N}$, Las Pilas $102^{\circ} 36^{\prime} 46^{\prime \prime O} 22^{\circ} 50^{\prime} 24^{\prime \prime} \mathrm{N}$, Los Ramírez $103^{\circ} 01^{\prime} 52^{\prime \prime} \mathrm{O} 23^{\circ} 50^{\prime} 49^{\prime \prime}{ }^{\prime \prime}$, Los Ángeles 102 ${ }^{\circ} 43^{\prime} 22^{\prime \prime O}$ $22^{\circ} 58^{\prime} 43^{\prime \prime} \mathrm{N}$, Noria De Agostadero $102^{\circ} 46^{\prime} 59^{\prime \prime} \mathrm{O}$ $22^{\circ} 53^{\prime} 14^{\prime \prime} \mathrm{N}$, Noria de los Gringos $102^{\circ} 43^{\prime} 04^{\prime \prime} \mathrm{O}$ $22^{\circ} 50^{\prime} 53^{\prime \prime} \mathrm{N}$, Puentecillos $102^{\circ} 45^{\prime} 03^{\prime \prime} \mathrm{O} 23^{\circ} 02^{\prime} 47^{\prime \prime} \mathrm{N}$,

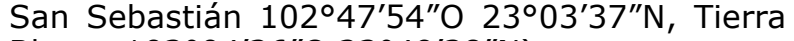
Blanca $103^{\circ} 04^{\prime} 36^{\prime \prime} \mathrm{O} 23^{\circ} 49^{\prime} 38^{\prime \prime} \mathrm{N}$ )

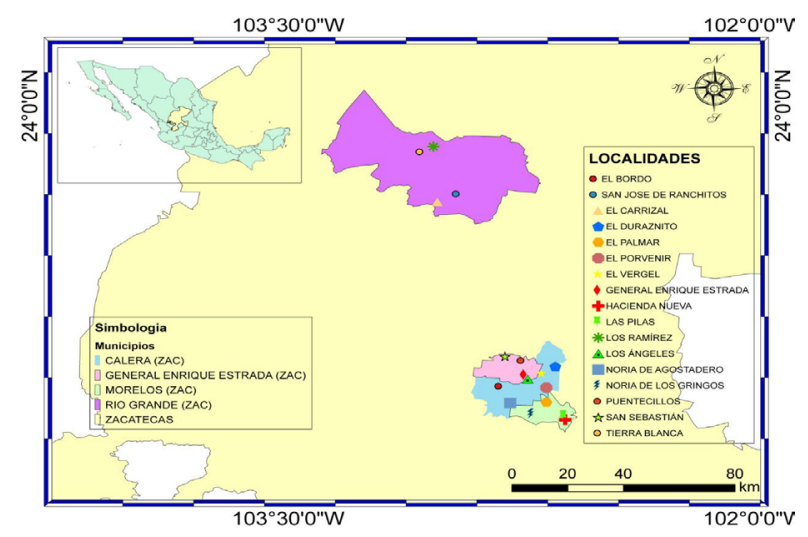

Figura 1. Ubicación geográfica de las localidades muestreadas en los cuatro municipios del estado de Zacatecas.

Cultivo de bacterias Gram negativas. Los cultivos se realizaron por duplicado. Cada muestra se sembró en caja petri con agar MacConkey (SMAC) las cuales fueron incubadas en una estufa bacteriológica a $37^{\circ} \mathrm{C}$ por 48 horas (12). Las colonias rosas cremosas se tomaron como positivas y éstas se aislaron individualmente para su posterior resiembra.

Identificación de bacterias en medio cromogénico $\mathrm{CHROMagar}^{\mathrm{TM}}$. Después de que las bacterias fueron aisladas en agar MacConkey se tomó una colonia para la identificación del serotipo de Escherichia coli O157:H7 o su variante no-móvil O157:H (serotipo VTEC), que es más común en salud pública. Se realizó la resiembra por estría en placa en medio cromogénico CHROMagar ${ }^{\mathrm{TM}}$ y se incubó a $37^{\circ} \mathrm{C}$ durante 24 horas (13), (Tabla 1).

Las colonias de Escherichia coli 0157:H7 crecen en CHROMagar ${ }^{\mathrm{TM}} \mathrm{O} 157$ y producen un color rosa malva debido a sustratos cromogénicos en el medio, permitiendo así, la identificación presuntiva de la placa de aislamiento primario y la diferenciación de otros organismos (13), (Tabla 1).

Tabla 1. Características de las colonias empleando el medio cromogénico CHROMagarTM.

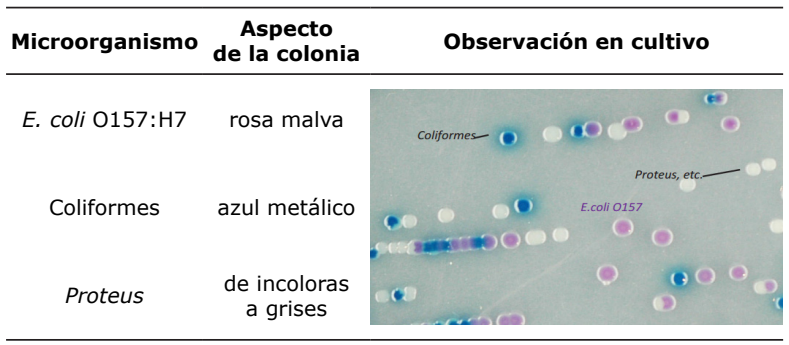

Análisis estadístico. Los datos experimentales se analizaron primero con estadística descriptiva y después se empleó una tabla de clasificación o tabla de contingencia. Se utilizó la prueba estadística Chi-cuadrada, esta es una estadística que permite determinar el grado de independencia entre las variables. El supuesto de esta prueba es: Ho: La prevalencia de las bacterias es independiente del tipo de rumiante que sea el portador; $\mathrm{Ha}$ : La prevalencia de las bacterias es dependiente del tipo de rumiante que sea el portador. El índice más importante de esta prueba es el valor p. En general, con valor $p$ menor de 0.05 se rechaza Ho y se concluye que las bacterias no son independientes. Todo el proceso estadístico se ejecutó con SPSS 25.0 para Microsoft Windows.

\section{RESULTADOS}

La determinación de Escherichia coli 0157:H7 se realizó con un medio cromogénico CHROMagar ${ }^{\mathrm{TM}}$ diferenciando las colonias bacterianas por color; Escherichia coli 0157:H7 presentó coloración rosa malva, Proteus ssp., son de incoloras a grises y los coliformes muestran colonias azul metálico como se puede apreciar en la figura 2.

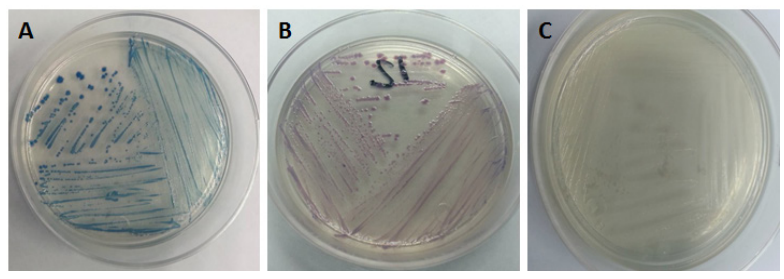

Figura 2. Desarrollo de las bacterias en CHROMagar ${ }^{\mathrm{TM}}$. A) Coliformes, B) E. coli O157:H7 y C) Proteus spp.

Algunas muestras presentaron desarrollo de dos o más colonias con distinta morfología y coloración, por lo que el número total de las colonias de 
bacterias identificadas fue de 354 y en 25 casos no hubo desarrollo en 24 horas, a pesar de que se encontró desarrollo en agar MacConkey y colonias con morfología descriptiva para Escherichia coli no hubo desarrollo en CHROMagar ${ }^{\mathrm{TM}}$.

Se identificaron 260 coliformes, 78 Escherichia coli 0157:H7 y 16 Proteus spp., en el total de los rumiantes muestreados, de los cuáles 183 fueron ovinos donde se encontró que en 46 de ellos había presencia de Escherichia coli O157:H7, en caprinos se encontraron 7 de 66 y en bovinos 25 de 67 como se muestra en la tabla 2. Además, usando la prueba Chi-cuadrado se comprobó que la prevalencia de las bacterias (coliformes, Escherichia coli O157:H7 y Proteus spp) depende del tipo de rumiante (ovino, bovino y caprino) que sea el portador de la bacteria (Tabla 3).

Tabla 2. Número de bacterias obtenidas de la siembra en CHROMagar ${ }^{\mathrm{TM}}$.

\begin{tabular}{ccccccc}
\hline Fuente & $\begin{array}{c}\# \\
\text { animales }\end{array}$ & Coliformes & $\begin{array}{c}\text { E. coli } \\
\text { O157:H7 }\end{array}$ & $\begin{array}{c}\text { Proteus } \\
\text { spp. }\end{array}$ & N D & $\begin{array}{c}\# \\
\text { bacterias }\end{array}$ \\
\hline Ovinos & 183 & 153 & 46 & 8 & 14 & 221 \\
Caprinos & 66 & 61 & 7 & 4 & 4 & 82 \\
Bovinos & 67 & 46 & 25 & 4 & 7 & 76 \\
Total & 316 & 260 & 78 & 16 & 25 & 379 \\
\hline
\end{tabular}

N.D.: No Determinados.

Tabla 3. Tabla de contingencia: tipo de bacteria vs tipo de rumiante.

\begin{tabular}{|c|c|c|c|c|c|}
\hline & \multicolumn{3}{|c|}{ Tipo de rumiante } & \multirow{2}{*}{ Total } \\
\hline & & Ovino & Bovino & Caprino & \\
\hline \multirow{8}{*}{$\begin{array}{l}\text { Prevalencia } \\
\text { de la bacteria }\end{array}$} & E. coli & 46 & 25 & 7 & 78 \\
\hline & O157:H7 & $20.8 \%$ & $30.5 \%$ & $9.2 \%$ & $20.6 \%$ \\
\hline & \multirow{2}{*}{ Coliformes } & 153 & 46 & 61 & 260 \\
\hline & & $69.2 \%$ & $56.1 \%$ & $80.3 \%$ & $68.6 \%$ \\
\hline & \multirow{2}{*}{ Proteus } & 8 & 4 & 4 & 16 \\
\hline & & $3.6 \%$ & $4.9 \%$ & $5.3 \%$ & $4.2 \%$ \\
\hline & \multirow{2}{*}{ N.D. } & 14 & 7 & 4 & 25 \\
\hline & & $6.3 \%$ & $8.5 \%$ & $5.3 \%$ & $6.6 \%$ \\
\hline \multirow{2}{*}{\multicolumn{2}{|c|}{ Total }} & 221 & 82 & 76 & 379 \\
\hline & & $100.0 \%$ & $100.0 \%$ & $100.0 \%$ & $100.0 \%$ \\
\hline
\end{tabular}

$\mathrm{H}_{\mathrm{o}}$ : La prevalencia de las bacterias es independiente del tipo de rumiante que sea el portador; $\mathrm{H}_{\mathrm{a}}$ : La prevalencia de las bacterias es dependiente del tipo de rumiante que sea el portador. Valor de Chi-cuadrada de Pearson $=13.243 . g l=6 ; p=0.039$. Como el valor de $p \leq 0.05$ se rechaza Ho. N.D.: No Determinados.

La distribución de bacterias encontradas según su localización geográfica corresponden a: 18 Escherichia coli O157:H7, 60 Coliformes y 7 Proteus ssp., en el municipio de Calera de Víctor Rosales; 40 Escherichia coli O157:H7, 11 Coliformes y 9 Proteus ssp., en localidades de Morelos, 24 Escherichia coli O157:H7, 41 Coliformes y 1 Proteus ssp., en localidades de General Enrique Estrada y 16 Escherichia coli 0157:H7, 99 Coliformes y 4 Proteus ssp., en localidades del municipio de Río Grande (Tabla 4).
Tabla 4. Bacterias determinadas por localidad y tipo de rumiante.

\begin{tabular}{|c|c|c|c|c|c|c|c|c|c|c|}
\hline \multirow[b]{2}{*}{ Municipios } & \multirow[b]{2}{*}{ Localidades } & \multicolumn{3}{|c|}{$\begin{array}{c}\text { E. coli } \\
0157: \mathrm{H7}\end{array}$} & \multicolumn{3}{|c|}{ Coliformes } & \multicolumn{3}{|c|}{ Proteus } \\
\hline & & $\begin{array}{l}\text { on } \\
\text { ó }\end{array}$ & 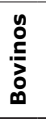 & 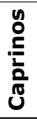 & ֻ气 & $\begin{array}{l}n \\
\stackrel{0}{c} \\
\stackrel{5}{3} \\
0 \\
0\end{array}$ & 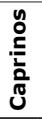 & రั & 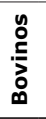 & 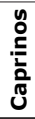 \\
\hline \multirow{5}{*}{$\begin{array}{l}\text { Calera } \\
\text { de Víctor } \\
\text { Rosales }\end{array}$} & El bordo & 1 & 0 & 0 & 9 & 1 & 2 & 1 & 0 & 0 \\
\hline & Noria de agostadero & 1 & 0 & 0 & 12 & 2 & 2 & 0 & 0 & 1 \\
\hline & El duraznillo & 5 & 4 & 1 & 5 & 1 & 1 & 1 & 0 & 0 \\
\hline & El porvenir & 5 & 0 & 0 & 11 & 2 & 3 & 0 & 1 & 1 \\
\hline & El vergel & 1 & 0 & 0 & 6 & 2 & 1 & 1 & 0 & 1 \\
\hline \multirow{4}{*}{ Morelos } & Hacienda Nueva & 2 & 0 & 0 & 3 & 3 & 3 & 0 & 1 & 0 \\
\hline & Noria de gringos & 3 & 0 & 2 & 20 & 5 & 1 & 0 & 1 & 0 \\
\hline & Las pilas & 2 & 1 & 0 & 4 & 1 & 4 & 1 & 0 & 0 \\
\hline & El palmar & 2 & 8 & 0 & 13 & 2 & 1 & 1 & 0 & 0 \\
\hline \multirow{4}{*}{$\begin{array}{l}\text { General } \\
\text { Enrique } \\
\text { Estrada }\end{array}$} & General Enrique Estrada & 3 & 0 & 0 & 3 & 2 & 3 & 0 & 0 & 0 \\
\hline & Los Ángeles & 5 & 0 & 0 & 2 & 1 & 3 & 0 & 0 & 0 \\
\hline & Puentecillos & 8 & 0 & 0 & 5 & 0 & 6 & 1 & 0 & 0 \\
\hline & San Sebastián & 4 & 3 & 1 & 8 & 5 & 3 & 0 & 0 & 0 \\
\hline \multirow{5}{*}{ Río Grande } & El carrizal & 0 & 0 & 0 & 8 & 4 & 6 & 1 & 0 & 0 \\
\hline & Los Ramírez & 4 & 0 & 3 & 9 & 3 & 7 & 1 & 0 & 0 \\
\hline & San José de Ranchitos & 0 & 5 & 0 & 16 & 7 & 7 & 0 & 1 & 1 \\
\hline & Tierra blanca & 0 & 4 & 0 & 19 & 5 & 8 & 0 & 0 & 0 \\
\hline & Total: & 46 & 25 & 7 & 153 & 46 & 61 & 8 & 4 & 4 \\
\hline
\end{tabular}

La mayor incidencia de bacterias fueron las coliformes con el $73.45 \%$ en los cuatro municipios, seguida de Escherichia coli 0157: H7 con el $22.03 \%$ y de Proteus el $4.52 \%$ (Tabla 5). Con estos resultados los ganaderos de la región están en condiciones de tomar la mejor decisión de prevención sobre el o los tratamientos que disminuyan la incidencia de este patógeno y con ello la mortalidad de rumiantes lactantes.

Tabla 5. Porcentaje de incidencia de bacterias por municipio y tipo de animal.

\begin{tabular}{|c|c|c|c|c|c|c|c|c|c|}
\hline \multirow[b]{2}{*}{ Municipios } & \multicolumn{3}{|c|}{$\begin{array}{c}\text { E. coli } \\
\text { 0157:H7 }\end{array}$} & \multicolumn{3}{|c|}{ Coliformes } & \multicolumn{3}{|c|}{ Proteus } \\
\hline & 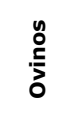 & 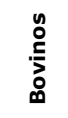 & 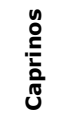 & o̊ & 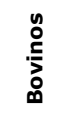 & 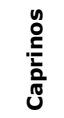 & $\frac{n}{\stackrel{c}{c}}$ & ๖̊ & 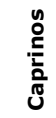 \\
\hline $\begin{array}{c}\text { Calera de Víctor } \\
\text { Rosales }\end{array}$ & 3.67 & 1.13 & 0.28 & 12.15 & 2.26 & 2.54 & 0.85 & 0.28 & 0.85 \\
\hline Morelos & 2.54 & 2.54 & 0.56 & 11.30 & 3.11 & 2.54 & 0.56 & 0.56 & 0.00 \\
\hline $\begin{array}{c}\text { General Enrique } \\
\text { Estrada }\end{array}$ & 5.65 & 0.85 & 0.28 & 5.08 & 2.26 & 4.24 & 0.28 & 0.00 & 0.00 \\
\hline Río Grande & 1.13 & 2.54 & 0.85 & 14.69 & 5.37 & 7.91 & 0.56 & 0.28 & 0.28 \\
\hline Incidencia \% & & $22.03 \%$ & & & $73.45 \%$ & & & $4.52 \%$ & \\
\hline
\end{tabular}




\section{DISCUSIÓN}

La presencia de la Escherichia coli $\mathrm{O} 157: \mathrm{H} 7$ en bovinos debe tenerse en consideración como un posible problema de salud pública, ya que esta bacteria está presente en las heces y esto constituye una fuente de infección para el hombre. En el proceso de sacrificio del animal, el refrigerado de la canal y también en el ordeño, es posible la contaminación de la carne y la leche respectivamente (14).

Se ha reportado que la presencia de Escherichia coli 0157:H7 en heces de bovino parece estar influenciada por la edad del animal (15). Por ejemplo, los terneros de menos de ocho semanas de edad (56 días) y novillas excretan más la cepa de Escherichia coli que el ganado adulto (16).

Escherichia coli 0157:H7 se ha convertido en un problema importante para la salud humana principalmente en los Estados Unidos de América (6); Olvera et al (16) han referido que el ganado vacuno es el reservorio primario de la bacteria Escherichia coli 0157:H7 causante de síndrome urémico hemolítico en humanos. En efecto, la canal proveniente del sistema de engorda de corral presenta la mayor incidencia de Escherichia coli verotoxigénica asociada al síndrome urémico hemolítico, en comparación con el sistema de pastoreo donde la vacunación redujo en un 54.1\% la contaminación de esta bacteria en carne bovina.

Para diagnosticar este patógeno, el aislamiento adecuado y los métodos de identificación son cruciales. Existe poca información disponible sobre su prevalencia en el manejo vaca/becerro. Sin embargo, en Louisiana, Estados Unidos de América, se reporta $8 \%$ de prevalencia de este patógeno, sin diferencias significativas entre materia fecal, agua (de canal y estanques) y frotis de superficie (de la cubeta de agua y del comedero) como fuente de contaminación (6).

En la investigación realizada por Fox et al (18) encontraron una prevalencia general de $62 \%$, más elevada que la obtenida en el presente trabajo (22.03\%). La prevalencia de Escherichia coli 0157: $\mathrm{H7}$ en el ganado es variable entre cada individuo y cada rebaño, en el ganado estabulado se puede encontrar en un rango del 10 al $28 \%$, pero puede ser más elevada, hasta el $80 \%$ en los meses de verano (19), el ganado vacuno es el más afectado, seguido de los ovinos (20), lo que indica que no hay selección de hospedero para Escherichia coli 0157:H7.

Con el uso del CHROMagarTM ha sido posible determinar la incidencia de forma rápida con una sensibilidad en su identificación del $98 \%$ y una especificidad del $100 \%$ (13), siendo superior al agar MacConkey sorbitol que, aun teniendo la misma sensibilidad, su especificidad disminuye al $85 \%$ y posee una precisión del $86 \%$. Este medio inicialmente se utilizaba sólo en la industria alimentaria para la liberación rápida de alimentos libres de patógenos, pero se ha probado para análisis de muestras clínicas y ha sido empleado en diversos estudios $(6,14,21,22)$. Sin embargo, para una exactitud del método se deberá continuar con la investigación, enfocándola hacia la caracterización basada en la secuencia de ácidos nucleicos mediante procedimientos de PCR (reacción en cadena de la polimerasa) que apunten a los genes de la toxina shiga (stx1 y stx2), ya que BBL CHROMagar O157 no hace diferencia entre las cepas de Escherichia coli O157:H7 productoras y no productoras de toxinas (13).

En conclusión, las bacterias coliformes fueron las de mayor presencia en las muestras analizadas, sin embargo, no son consideradas como el agente causal de diarrea. La presencia de Escherichia coli 0157:H7 fue la segunda bacteria con mayor porcentaje en las muestras de heces analizadas ( $22.03 \%$ de incidencia), lo cual no depende de la especie del rumiante, pero representa un factor de riesgo de muerte en rumiantes lactantes (menos de 21 días de nacidos) causando pérdidas económicas y riesgo para la salud de la población del estado de Zacatecas.

\section{Conflicto de intereses.}

Los autores del presente estudio declaramos que no existe conflicto de intereses con la publicación de este manuscrito.

\section{REFERENCIAS}

1. WHO. Zoonotic Non-0157 Shiga ToxinProducing Escherichia Coli (STEC): report of a WHO scientific working group meeting, Berlin, Germany. (No. WHO/CSR/APH/98.8). Geneva: World Health Organization; 1998. https://apps.who.int/iris/bitstream/ handle/10665/68880/WHO CSR APH 98.8. pdf;jsessionid=B1067243252676E852A98B 9BF9EB08C3? sequence $=1$
2. Méndez A, Maldonado A, Ruiz-Villamor ER, Moreno IL, Bautista MJ, Lorenzo B, et al. Enfermedades neonatales. [On line] Organismo De La Unidad Nacional De Ovinocultores: México; 2016. http://www. uno.org. mx/empezar/neonatales.html 
3. Macedo R, Arredondo V, Rodríguez J, Ramírez J, López, B. Efecto del sistema de producción, de la época de nacimiento y del sexo sobre la mortalidad neonatal de corderos Pelibuey. Trop Subtrop Agroecosyst. 2010; 12(1):7784. http://www.revista.ccba.uady.mx/ojs/ index.php/TSA/article/view/205

4. Gebremedhin EZ, Agonafir A, Tessema TS, Tilahun G, Medhin G, Vitale M. et al. Some risk factors for reproductive failures and contribution of Toxoplasma gondii infection in sheep and goats of Central Ethiopia: a cross-sectional study. Res Vet Sci. 2013; 95(3):894-900. https://doi.org/10.1016/j. rvsc. 2013.08 .007

5. Gould LH, Bopp C, Strockbine N, Atkinson R, Baselski V, Body B. et al. Recommendations for diagnosis of Shiga toxin-producing Escherichia coli infections by clinical laboratories. MMWR Recomm Rep. 2009; 58(12) 1-14. https:// www.cdc.gov/mmwr/preview/mmwrhtml/ rr5812a1.htm

6. Gutierrez ME, Janes ME, Torrico DD, Carabante KM, Prinyawiwatkul W. Assessment of the ability of five culture media for the detection of Escherichia coli 0157. Int J Food Sci Technol. 2016; 51(8):1910-1915. https:// doi.org/10.1111/ijfs.13164

7. Laven RA, Ashmore A, Stewart CS. Escherichia coli in the rumen and colon of slaughter cattle, with particular reference to $\mathrm{E}$. coli O157. Vet. J. 2003; 165 78-83. https://doi.org/10.1016/ S1090-0233(02)00162-4

8. Bertin Y, Girardeau JP, Chaucheyras-Durand F, Lyan B, Pujos-Guillot E, Harel J. et al. Enterohaemorrhagic Escherichia coli gains a competitive advantage by using ethanolamine as a nitrogen source in the bovine intestinal content. Environ Microbiol. 2011; 13(2):365377. https://doi.org/10.1111/j.1462$\underline{2920.2010 .02334 . x}$

9. Cobbold RN. Rectoanal junction colonization of feedlot cattle by Escherichia coli 0157:H7 and its association with supershedders and excretion dynamics. Appl Environ Microbiol. 2007; 73(5):1563-1568. https:// doi.org/10.1128/AEM.01742-06

10. Franz $E$, van Hoek $A H$, van der Wal FJ, de Boer A, Zwartkruis-Nahuis A, van der Zwaluw $K$. et al. Genetic features differentiating bovine, food and human isolates of Shiga toxin-producing Escherichia coli 0157 in The Netherlands. J Clin Microbiol. 2012; 50(3):772-780. http://dx.doi.org/10.1128/ JCM.05964-11
11. Fratamico PM, DebRoy C. Detection of Escherichia coli O157:H7 in food using realtime multiplex PCR assays targeting the stx 1 , stx2, wzyO157, and the flich7 or eae genes. Food Anal Methods. 2010; 3(4):330-337. https://doi.org/10.1007/s12161-010-9140-x

12. Vicente HIG, Amaral LA, Cerqueira AMF. Shigatoxigenic Escherichia coli serogroups O157, 0111 and 0113 in feces, water and milk samples from dairy farms. Braz J Microbiol. 2005; 36(3):217-222. http://dx.doi. org/10.1590/S1517-83822005000300003

13. Hirvonen JJ, Siitonen A, Kaukoranta SS. Usability and performance of CHROMagar STEC in detection of Shiga toxin-producing Escherichia coli strains. J Clin Microbiol. 2012; 50:3586-3590. https://doi.org/10.1128/ JCM.01754-12

14. Etcheverria AI, Padola NL. Shiga toxin-producing Escherichia coli: factors involved in virulence and cattle colonization. Virulence. 2013; 4(5):366-372. https://doi.org/10.4161/ viru. 24642

15. Caballero M, Rivera I, Jara LM, UlloaStanojlovic FM, Shiva C. Isolation and molecular identification of potentially pathogenic Escherichia coli and Campylobacter jejuni in feral pigeons from an urban area in the city of Lima, Peru. Rev Inst Med Trop S Paulo. 2015; 57(5):393-396. http://dx.doi. org/10.1590/S0036-46652015000500004

16. Heiman KE, Mody RK, Johnson SD, Griffin PM, Gould LH. Escherichia coli O157 outbreaks in the United States, 2003-2012. Emerg Infect Dis. 2015; 21(8):1293-1301. https://doi. org/10.3201/eid2108.141364

17. Olvera A, Signorini M, Tarabla H. Escherichia coli verotoxigénica: modelo cuantitativo de exposición y escenarios de riesgos en canales bovinas en Argentina. Rev Panam Salud Pública. 2010; 27(6):403-413. https://doi. org/10.1590/S1020-49892010000600001

18. Fox JT, Shi X, Nagaraja TG. Escherichia coli 0157 in the rectoanal mucosal region of cattle. Foodborne Pathog Dis. 2008; 5(1):6977. https://doi.org/10.1089/fpd.2008.0042

19. Jacob ME, Callaway TR, Nagaraja TG. Dietary interactions and interventions affecting Escherichia coli 0157 colonization and shedding in cattle. Foodborne Pathog Dis. $2009 ; 6(7): 785-792$. https://doi. org/10.1089/fpd.2009.0306 
20. Piedrahita D, Márquez T, Máttar S. Detección de Escherichia coli 0157: H7 en poblaciones porcinas, canal bovina y productos cárnicos en el departamento de Córdoba. Rev MVZ Córdoba. 2001; 6(2):119-126: https://doi. org/10.21897/rmvz.532

21. Tang $Y$, Kim $H$, Singh AK, Aroonnual A, Bae E, Rajwa B. et al. Light scattering sensor for direct identification of colonies of Escherichia coli serogroups 026, 045, 0103, 0111, 0121, 0145 and 0157. PloS One. 2014; 9(8):e105272. https://journals. plos.org/plosone/article?id=10.1371/journal. pone.0105272
22. Parsons BD, Zelyas N, Berenger BM, Chui L. Detection, characterization, and typing of Shiga toxin-producing Escherichia coli. Front Microbiol. 2016; 7:478. https://doi. org/10.3389/fmicb.2016.00478 